\title{
Correction to: Measuring the Accessibility of Railway Stations in the Brussels Regional Express Network: a Node-Place Modeling Approach
}

\author{
Freke Caset $^{1,2}$ (D) David S. Vale ${ }^{3} \cdot$ Cláudia M. Viana $^{3}$ \\ Published online: 20 August 2018 \\ (C) Springer Science+Business Media, LLC, part of Springer Nature 2018
}

\section{Correction to: Netw Spat Econ \\ https://doi.org/10.1007/s11067-018-9409-y}

The original version of this article unfortunately contained a mistake. The article title should read as "Measuring the Accessibility of Railway Stations in the Brussels Regional Express Network: a Node-Place Modeling Approach".

The original article has been corrected.

The online version of the original article can be found at https://doi.org/10.1007/s11067-018-9409-y

Freke Caset

freke.caset@ugent.be

David S. Vale

dvale@fa.ulisboa.pt

Cláudia M. Viana

claudiaviana@campus.ul.pt

1 Ghent University, Krijgslaan 281, 9000 Ghent, Belgium

2 Vrije Universiteit Brussel, Cosmopolis Centre for Urban Research, Pleinlaan 2, 1050 Brussels, Belgium

3 CIAUD, Faculty of Architecture, University of Lisbon (Rua Sá Nogueira), 1349-063 Lisbon, Portugal 